\title{
The coast road
}

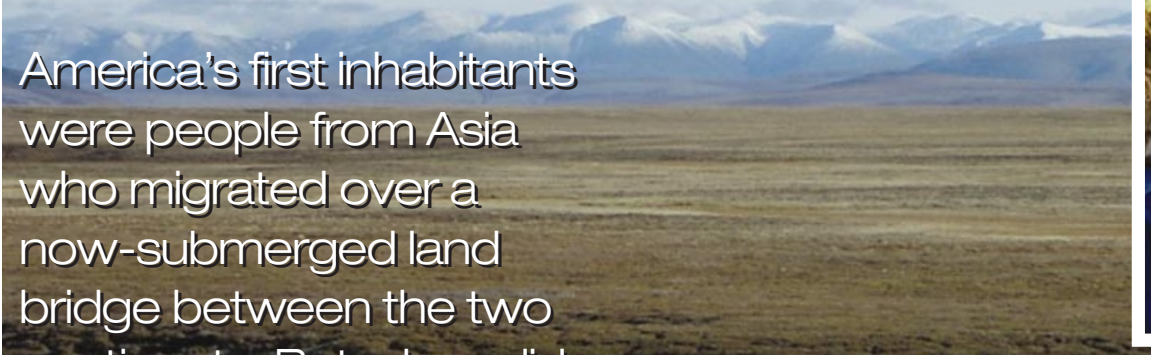

continents. But when did

they come, and where did

they go after making their

crossing? Rex Dalton

reports.

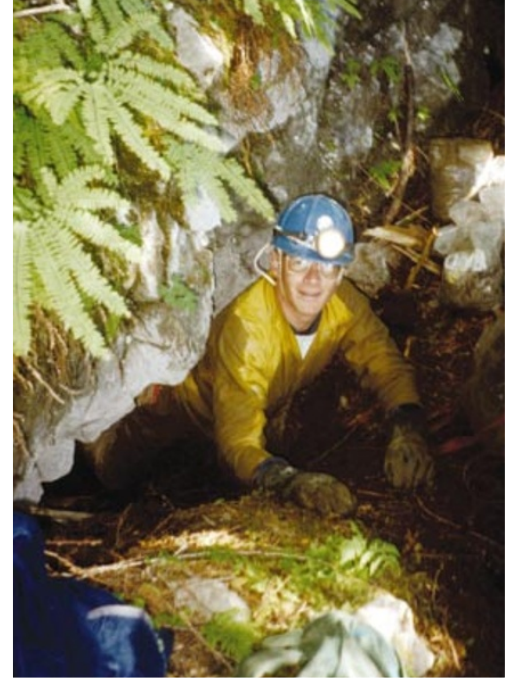

Going underground: Timothy Heaton hopes that his summer caving expeditions in Alaska will shed light on the route taken by the first Americans, who hiked across a desolate strip of tundra thousands of years ago

A

long the storm-lashed coast of southeast Alaska, where dense forests shroud weather-pocked limestone formations, Timothy Heaton spends his summers prowling remote islands in search of a special cave. He drops into sinkholes, squirms through narrow tunnels, and probes the sediments of underground caverns.

The object of his dirty, challenging quest is a cave containing specimens that will answer one of the great mysteries surrounding the peopling of the Americas: the date at which the first human colonists crossed from Asia over a land bridge that now lies submerged beneath the Bering and Chukchi Seas, and where the travellers went after that.

Heaton, a vertebrate palaeontologist at the University of South Dakota at Vermillion, is one of a growing number of experts who believe that the first Americans migrated along the Pacific Coast among the islands and bays of Alaska and Canada, at a time when the North American interior was an inhospitable, ice-covered wasteland. Recent discoveries have cast doubt on the conventional wisdom that North America was first colonized by a culture of big-game hunters called the Clovis, who ventured south across the continent's central plains only after the ice sheets retreated, reaching what is now the southwestern United States at least 11,500 years ago.

Now there is an explosion of interest in studying the climatic, environmental and geological conditions that prevailed along the Pacific Coast during the past 35,000 years or so. Investigators have high hopes of finding physical traces of early coastal migrants, some of whom may have preceded the Clovis by many thousands of years. "We are just ramping up to nail down issues about the coastal route," says Julie Brigham-Grette, a geologist at the University of Massachusetts at Amherst.

Already, Heaton and his colleagues from the Institute of Arctic and Alpine Research (INSTAAR) at the University of Colorado, Boulder, have found a man-made tool that they have radiocarbon dated to about 10,300 years ago in a cave on Prince of Wales Island, southeast Alaska ${ }^{1}$. They have also found bear specimens dating back some 41,000 years ${ }^{2}$ which is tantalizing, because where bears can live, so can people.

\section{Who came first?}

Archaeological discoveries made in New Mexico in the 1920s - in particular, distinctive fluted projectile points dating from 11,500 years ago - identified the Clovis as the first known Americans ${ }^{3}$. The timing seemed to make sense: before the ice melted, no one would have been able to migrate across the continent's frozen interior. And until about 2,500 years before the Clovis arrived in New Mexico, ice sheets extended throughout Canada and into the northern United States.

But more recent findings in South America have demolished the status of the Clovis as the original American pioneers. A quarter of a century ago, anthropologist Thomas Dillehay, now at the University of Kentucky in Lexington, made an astonishing claim: that a group of hunter-gatherers was well established at a site called Monte Verde in Chile 12,500 years ago ${ }^{4}$. For many years, the radio- carbon dating of Dillehay's specimens was disputed. But in 1997, Dillehay published a detailed monograph on the Monte Verde site $^{5}$ that silenced his critics once and for all.

If people had migrated almost to the tip of South America by 12,500 years ago, experts agree they must have begun trekking south from Alaska before the glaciers retreated from the American interior. So in the past few years, attention has turned to the coastal route, where the moderating influence of the Pacific Ocean may have kept conditions fit for human habitation. "We are seeing a major paradigm shift," says James Dixon, an archaeologist at INSTAAR who has investigated caves with Heaton.

Confirming the coastal route is no easy matter, however. The terrain is forbidding, harsh winters restrict field studies to the summer months, and much of what was then the Pacific Coast of North America is now underwater. When the glaciers finally melted, the sea level rose by some 125 metres, covering both the land bridge from which the first American colonists migrated from Asia - a strip of tundra some 1,000 kilometres wide known as Beringia - and regions that now lie on the coastal shelf off southeast Alaska and British Columbia.

Last summer, a team of 20 scientists from five US institutions began the most ambitious study yet of Beringia. Led by Brigham-Grette, together with Lloyd Keigwin, a palaeoclimatologist at the Woods Hole Oceanographic Institution in Massachusetts, and Neal Driscoll, a geologist at the Scripps Institution of Oceanography in La Jolla, California, they sailed aboard the Healy, a new icebreaker operated by the US Coast Guard, to the Bering 

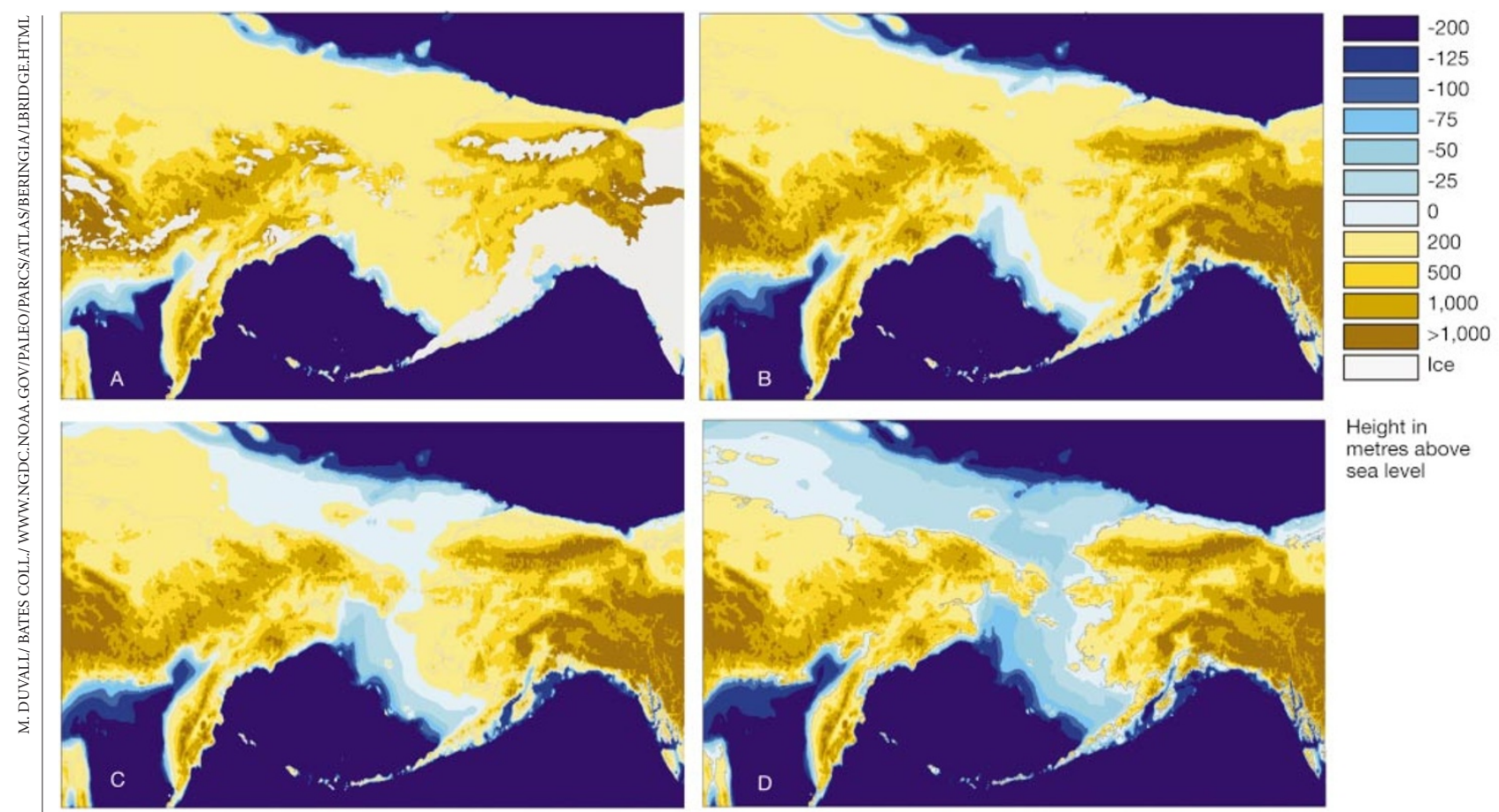

Height in

metres above

sea level

Bridging the gap: calculations of sea levels 18,000 years ago (top left) and 10,200 years ago (top right) show that a land bridge existed between modern Siberia and Alaska. By 8,900 years ago (above left) this land was submerged, creating today's Bering Strait (above right). Quoted ages are calibrated for consistency with archaeological radiocarbon dates, as given in the text.

and Chukchi Seas (see map, below right). There, the researchers collected cylindrical sediment samples, or cores, from the nowsubmerged land bridge and the neighbouring ocean floor. Previously, the Chukchi Sea's persistent ice had prevented studies. But in the event, unusually warm conditions meant that the Healy's ice-breaking capabilities were not required. "It was embarrassing," confides Brigham-Grette. "We waited for an ice cutter and there was no ice."

Steaming back and forth across the region over two cruises, each lasting three weeks, the Healy's scientific crew pulled more than 100 cores from the sea floor. Some were at depths of 40-120 metres below the surface, on the former land bridge, whereas others came from depths of up to 2,500 metres in the deeper waters to the north and south. Now stored at Woods Hole, the cores will be subjected to extensive analysis to ascertain the climate, environmental conditions and sea level over the past 20,000 years. Research on the samples should determine, for instance, what portions of the land bridge were above water at what times.

Selecting sites for drilling, and obtaining intact cores, required some sophisticated technology. The scientists were particularly interested in sampling from former river valleys that are now submerged on the coastal shelf in the Chukchi Sea. But the valleys are overlaid by marine sediment, and are therefore hard to spot. Extracting intact samples from both marine and river sediments is also challenging because of their high sand content - which means that the cores are likely to fall apart when pulled from the ocean floor.

A state-of-the-art sonar device, called SUBSCAN, allowed the team to find the submerged river valleys. SUBSCAN - a bat-winged affair the size of a desktop — was developed by Driscoll, together with Steven Schock of the Florida Atlantic University in Boca Raton and a company called EdgeTech in the same city. Towed behind the Healy some 40 metres above the sea floor, SUBSCAN emits an acoustic pulse that penetrates the sea floor to a depth of 40 metres in sand, and to 100 metres in clay or silt. The device features an advanced system for analysing the reflected sound that allows it to build up an image of the sedimentary layers, from which the researchers can discern the difference between river and marine sediments. "The resolution of the images produced is just dynamite," says BrighamGrette, who notes that they clearly reveal the elusive V-shaped river valleys.

To ensure that sandy cores didn't disintegrate, the Healy researchers used a device that was developed at the Coastal Carolina University in Conway, South Carolina. The apparatus is named 'Taz' after the Warner Brothers cartoon character, because of its dervish-like whirling action. After being lowered to the sea floor by a cable, Taz's two counter-rotating electric hammers produce a vibrating motion that forces a tube down into the sediment without disturbing the captured material. In conventional methods, a heavily weighted tube is driven into the ocean floor and pulled up with the core inside. But a sandy core has a tendency to fall out of the tube, so the Taz tubes feature 'fingers' at the bottom and also use suction to hold the sediment intact inside.

Although some 20 cores were pulled from

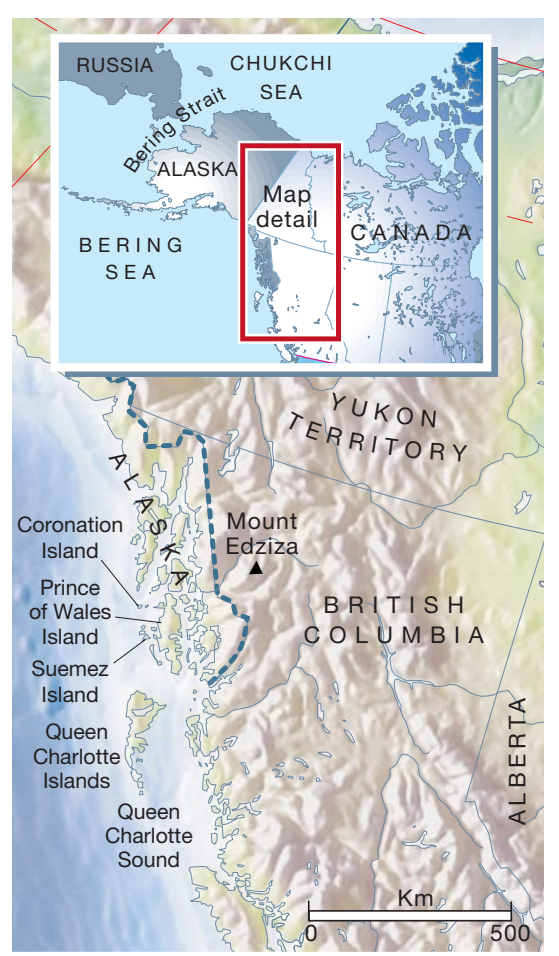


